\title{
Amyloid Pathology Is Associated with Progressive Monoaminergic Neurodegeneration in a Transgenic Mouse Model of Alzheimer's Disease
}

\author{
Ying Liu, ${ }^{1}$ Mi-Jeong Yoo, ${ }^{1}$ Alena Savonenko, ${ }^{1}$ Wanda Stirling, ${ }^{1}$ Donald L. Price, ${ }^{1,2,3}$ David R. Borchelt, ${ }^{1,3}$ \\ Laura Mamounas, ${ }^{1}$ W. Ernest Lyons, ${ }^{1}$ Mary E. Blue, ${ }^{2,3,4}$ and Michael K. Lee ${ }^{1}$ \\ Departments of ${ }^{1}$ Pathology, ${ }^{2}$ Neurology, and ${ }^{3}$ Neuroscience, Johns Hopkins University, Baltimore, Maryland 21205, and ${ }^{4}$ Kennedy Krieger Research \\ Institute, Baltimore, Maryland 21205
}

\begin{abstract}
$\beta$-Amyloid $(\mathrm{A} \beta$ ) pathology is an essential pathogenic component in Alzheimer's disease (AD). However, the significance of $\mathrm{A} \beta$ pathology, including $\mathrm{A} \beta$ deposits/oligomers and glial reactions, to neurodegeneration is unclear. In particular, despite the $\mathrm{A} \beta$ neurotoxicity indicated by in vitro studies, mouse models with significant $\mathrm{A} \beta$ deposition lack robust and progressive loss of forebrain neurons. Such results have fueled the view that $\mathrm{A} \beta$ pathology is insufficient for neurodegeneration in vivo. In this study, because monoaminergic (MAergic) neurons show degenerative changes at early stages of $\mathrm{AD}$, we examined whether the APPswe/PS1 $\triangle E 9$ mouse model recapitulates progressive MAergic neurodegeneration occurring in $\mathrm{AD}$ cases. We show that the progression forebrain $\mathrm{A} \beta$ deposition in the APPswe/ $P S 1 \Delta E 9$ model is associated with progressive losses of the forebrain MAergic afferents. Significantly, axonal degeneration is associated with significant atrophy of cell bodies and eventually leads to robust loss $(\sim 50 \%)$ of subcortical MAergic neurons. Degeneration of these neurons occurs without obvious local $\mathrm{A} \beta$ or tau pathology at the subcortical sites and precedes the onset of anxiety-associated behavior in the mice. Our results show that a transgenic mouse model of $\mathrm{A} \beta$ pathology develops progressive MAergic neurodegeneration occurring in $\mathrm{AD}$ cases.
\end{abstract}

Key words: A $\beta$-peptide; axon; serotonergic; noradrenergic; neuron death; BDNF; atrophy

\section{Introduction}

Alzheimer's disease (AD) is characterized by dementia and degeneration of multiple neuronal populations in which $\beta$-amyloid $(\mathrm{A} \beta)$-related abnormalities are early and necessary pathogenic events (Sisodia and George-Hyslop, 2002). The role of $\mathrm{A} \beta$ as a primary pathogenic and neurodegenerative agent in $\mathrm{AD}$ is supported by numerous in vitro cell culture studies showing that $\mathrm{A} \beta$ either is directly neurotoxic and/or exacerbates the effects of secondary insults (Mattson, 1995; Yankner, 1996). With the development of transgenic ( $\mathrm{Tg}$ ) mouse models of cerebral A $\beta$ deposition (McGowan et al., 2006), it was hoped that these mice will develop overt $\mathrm{A} \beta$-dependent neurodegeneration in vivo. However, the results from $\mathrm{Tg}$ mice show either lack of robust neurodegeneration with A $\beta$ pathology (Irizarry et al., 1997a,b; Calhoun

Received Sept. 4, 2008; revised 0ct. 7, 2008; accepted Nov. 3, 2008.

This work was supported by a Pilot Project Award (M.K.L.) from Johns Hopkins Alzheimer's Disease Research Center, an Investigator Initiated Research Grant from the Azheimer's Association (M.K.L.), and a Postdoctoral Fellowship from the Adler Foundation (Y.L.). We thank Oliva Lee and Dr. Bobby Thomas for technical assistance.

Correspondence should be addressed to Dr. Michael K. Lee, Department of Pathology/Neuropathology, Johns Hopkins University School of Medicine, 720 Rutland Avenue, 558 Ross Building, Baltimore, MD 21205. E-mail: mklee@jhmi.edu.

D. R. Borchelt's present address: Department of Neuroscience, McKnight Brain Institute, University of Florida, Gainesville, FL 32611.

L. Mamounas's and W. E. Lyons's present address: National Institute of Neurological Disorders and StrokeNational Institutes of Health, Bethesda, MD 20892.

DOI:10.1523/JNEUROSCI.4218-08.2008

Copyright $\odot 2008$ Society for Neuroscience ～0270-6474/08/2813805-10\$15.00/0 et al., 1998; Wong et al., 1999; Boncristiano et al., 2002; Schmitz et al., 2004) or modest (10-30\%) loss of cortical/hippocampal neurons with prolonged $\mathrm{A} \beta$ pathology (Calhoun et al., 1998; Schmitz et al., 2004). These results contribute to the view that $\mathrm{A} \beta$ pathology is not sufficient to cause neurodegeneration in vivo (McGowan et al., 2006). One current view is that neurofibrillary tangle pathology, comprising hyperphosphorylated tau, is critical for $\mathrm{AD}$-associated neurodegeneration, but this is lacking in $\mathrm{A} \beta$ Tg models.

In addition to the degeneration of cortical and hippocampal neurons, $\mathrm{AD}$ is associated with the early and progressive degeneration of monoaminergic (MAergic) neurons [serotonergic (5$\mathrm{HT}$ ) neurons in the raphe and the noradrenergic (NA) neurons in the locus ceruleus (LC)] (Marcyniuk et al., 1986; Zweig et al., 1988; German et al., 1992; Rub et al., 2000; Parvizi et al., 2001; Lyness et al., 2003; Grudzien et al., 2007). Analysis of MAergic neuropathology in $\mathrm{AD}$ cases indicate that neurons that project to cortex (anterior raphe/LC) are pathologically affected, whereas neurons without cortical projections (posterior raphe/LC) are free of pathological changes (Marcyniuk et al., 1986; German et al., 1992; Parvizi et al., 2001). A simple explanation is that the pathological changes in cortex, such as amyloid deposition and inflammation, leads to degeneration of the brainstem MAergic neurons. Significantly, degeneration of NA neurons may contribute to the progression of amyloid pathology in brain (Heneka et al., 2006; Kalinin et al., 2007), and abnormalities in MAergic 
systems may underlie cognitive and noncognitive abnormalities of $\mathrm{AD}$. Given this background, we hypothesized that $\mathrm{A} \beta$ pathology may be linked to degeneration of the MAergic system in the APPswe/PS1 $\triangle E 9$ mouse model of amyloidosis (Jankowsky et al., 2004; Savonenko et al., 2005b). Furthermore, if distal axonopathy-like neurodegeneration and/or defects in trophic signaling in response to cortical abnormalities are involved in $\mathrm{A} \beta$-dependent neurodegeneration, we believe MAergic neurons would exhibit increased vulnerability to neurodegeneration because MA neurons have long and profuse afferents into the forebrain regions that develop significant $\mathrm{A} \beta$ deposition.

Here, we show that progressive $A \beta$ deposition in forebrains of the APPswe/PS1 $\triangle E 9$ mouse model is associated with progressive degeneration of MAergic afferents, ultimately leading to the demise of MAergic neurons in midbrain and in brainstem. Overall, we show that a $\mathrm{Tg}$ mouse model of $\mathrm{A} \beta$ pathology can exhibit robust and progressive neurodegeneration without obvious neurofibrillary pathology.

\section{Materials and Methods}

Subjects. Tg and non-Tg mice of all possible genotypes were generated by mating MoPrp-Mo/Hu APPswe (line 3-3) with MoPrp-PS1 $1 E 9$ (line S9) $\mathrm{Tg}$ mice as described previously (Savonenko et al., 2005a). The Institutional Animal Care and Use Committee of the Johns Hopkins University approved the studies and conducted them in strict compliance with the National Institutes of Health Guide for the Care and Use of Laboratory Animals.

Immunocytochemistry. For histological analysis, the mice were perfused intracardially with $4 \%$ paraformaldehyde. Brains were cryoprotected, and serial frozen coronal sections $(30 \mu \mathrm{m})$ were serially distributed into individual wells of 96 -well plates. To facilitate the identification of regions of interest for the quantitative stereological analysis, every 24th section through the entire brain was Nissl stained and compared with the stereotaxic coordinates of the mouse brain (Paxinos and Franklin, 2001).

To detect 5-HT fibers and neurons, free-floating frozen sections (30 $\mu \mathrm{m})$ were immunoreacted with an anti-5-HT antiserum (Immunostar), followed by the ABC method (Vector Laboratories) using diaminobenzidine (DAB) as the chromogen. The NA and dopaminergic (DA) fibers/ neurons were visualized using an anti-tyrosine hydroxylase (TH) antibody (Novus Biologicals). In some cases, silver-gold intensification of immunoreactive fibers facilitated the identification of MAergic fibers (Mamounas et al., 2000).

$\mathrm{A} \beta$ and amyloid deposits were visualized using anti-A $\beta$ mouse monoclonal antibodies $(4 \mathrm{G} 8,6 \mathrm{E} 10)$ or rabbit anti-A $\beta 42$ antibodies (BioSource). Phosphorylated tau was detected using AT8 (Pierce), a monoclonal antibody specific for phosphorylated Ser202, or PHF-1 (gift from Dr. P. Davies, Albert Einstein College of Medicine, New York, NY), a monoclonal antibody specific for phosphoserines 396/404. Antibodies to Ibal (Wako) and GFAP (Dako) were used to define microglia and astocytes, respectively. For double-immunocytochemical analysis using light microscopy, first primary antibodies were detected using DAB, followed by incubation with second primary antibodies and detection using the SG chromogenic substrate kit (SK-4700; Vector Laboratories).

For double-immunofluorescence analysis of antigens, bound primary antibodies were visualized with appropriate secondary antibodies conjugated to either $\mathrm{Cy} 2$ or $\mathrm{Cy} 3$. Immunoreactive structures were visualized by confocal microscopy using a LSM510-META system (Zeiss).

Stereological analysis of fiber length/density. The stereological length estimation with spherical probes (Stereo Investigator; MicroBrightField) was used to determine the length of MAergic fibers (Mouton et al., 2002). Briefly, virtual spherical probes were placed within a thick section, and intersection of immunoreactive fibers with the sphere was counted. The lengths were measured at 50 random locations through the reference space. At each focal plane, concentric circles of progressively increasing and decreasing diameters were superimposed, and the intersections with the immunoreactive fibers and circles were counted $(Q)$. To minimize surface artifacts, a guard volume of $1 \mu \mathrm{m}$ was used. This method allows for simple determination of the total length density $\left(L_{V}\right)$ and the total length $(L)$. To reduce the effects of variations in the area selection, $L_{V}$ was routinely used for comparison between groups.

Because the densities of MAergic afferents can show significant regional and rostrocaudal heterogeneity, we focused our analysis on the selected subregions defined by The Mouse Brain in Sterotaxic Coordinates (Paxinos and Franklin, 2001). For each neurotransmitter marker, every eighth section, from the randomly selected start within the first eight sections through the entire region of interest, was processed for immunocytochemistry. The following regions were examined: barrel field region of primary somatosensory cortex (S1BF; sections between bregma -0.10 to $-1.22 \mathrm{~mm}$, posterior to anterior commissure and anterior to hippocampus), primary motor cortex (M1; bregma 1.42-0.5 mm), amygdala (bregma -1.34 to $-2.06 \mathrm{~mm}$ ), and dorsal hippocampus (dentate, CA1, CA2/3; sections between bregma -1.46 to $-2.18 \mathrm{~mm}$ ). Post hoc analysis shows $<10 \%$ variation between different genotypes in the average volumes of the areas examined. Table 1 shows the parameters used for stereology.

Stereological analysis of neuron number and size. For the analysis, every fourth section through the entire region containing LC, raphe, or substantia nigra, par compacta (SNpc)/ventral tegmental area (VTA) were immunostained and counterstained for Nissl. The total neuron numbers were estimated using the optical fractionator (StereoInvestigator; MicroBrightField) (Gundersen et al., 1988a,b; Mayhew, 1992). In general, we used a $40 \times 40 \mu \mathrm{m}$ counting frame, a $1 \mu \mathrm{m}$ guard, a $130 \times 130 \mu \mathrm{m}$ sampling grid, and a dissector height of $10 \mu \mathrm{m}$.

For unbiased stereological analysis of neuronal size (area and volume), neurons were randomly sampled within the region of interest using the sections used for cell counting (at least 50 neurons per section). Neuronal size was determined using the vertical nucleator probe. The area/volume of neuronal cell bodies were determined by placing four rays through the nucleolus. The cells were measured if their nuclear membrane intersected or touched the inclusion (green) line. The cells were excluded if the nuclear membrane intersected or touched the exclusion (red) line. The measuring rays were "cut" at the intersection with the cell membrane. If a ray extended into a dendrite, the ray was cut at the base of the dendrite. Table 1 shows the stereology parameters used.

HPLC-electrochemical analysis of neurotransmitters. The concentrations of biogenic amines in discrete brain regions were determined by HPLC with electrochemical detection (Thomas et al., 2007). Briefly, the tissue was weighed and sonicated in $0.2 \mathrm{ml}$ of $0.1 \mathrm{M}$ perchloric acid containing $0.01 \%$ EDTA and $25 \mu \mathrm{g} / \mathrm{ml} \mathrm{3,4-dihydroxybenzylamine}$ (Sigma) as an internal standard. After centrifugation $(15,000 \times g, 10 \mathrm{~min}$, $\left.4^{\circ} \mathrm{C}\right), 20 \mu \mathrm{l}$ of the supernatant was injected onto a C-18 reverse-phase column (Spheri-5, RP-18, $4.6 \mathrm{~mm} \times 25 \mathrm{~cm}$ catecholamine column; BASi). The mobile phase consisted of $0.15 \mathrm{~m}$ chloroacetic acid, $0.2 \mathrm{~mm}$ 

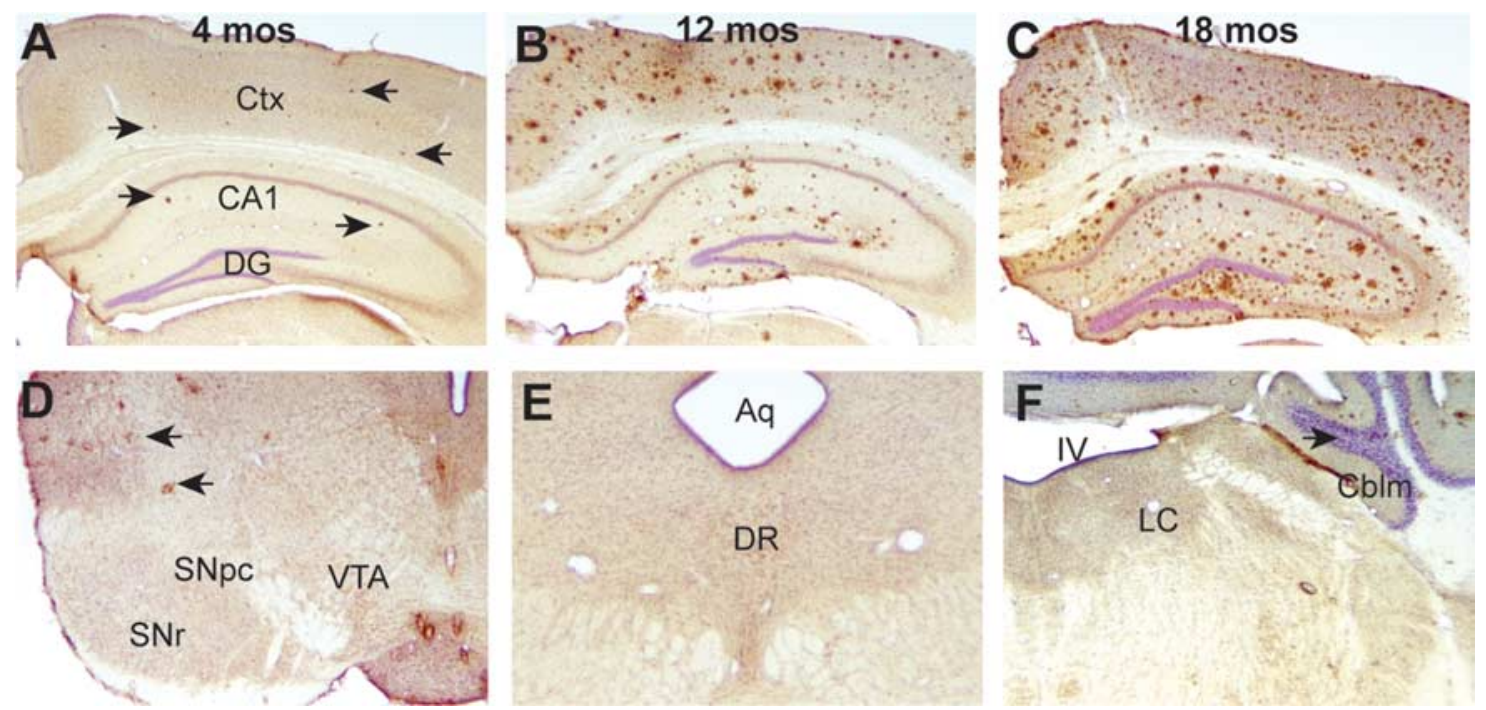

Figure 1. Progressive $A \beta$ deposition in APPswe/PS1 $1 E 9$ mice. $A-C$, Coronal brain sections from 4-, 12-, and 18-month-old APPswe/PS1 $\triangle E 9$ Tg mice immunostained for $A \beta$ (antibody $4 G 8$ ). An increase in the $A \beta$ deposits with aging is apparent in cortex (Ctx) and hippocampus (CA1; DG, dentate gyrus). Few $A \beta$ deposits ( $\boldsymbol{A}$, arrows) are seen at 4 months of age. mos, Months. $\boldsymbol{D}-\boldsymbol{F}$, $A \beta$ immunostaining of brain sections from 18-month-old APPswe/PS1 $\triangle E 9$ mice containing ventral midbrain ( $\boldsymbol{D} ;$ SNr, substantia nigra pars reticulate), dorsal raphe (DR; $\boldsymbol{E})$, and LC $(\boldsymbol{F})$. Except for a few $A \beta$ deposits (arrows in $\boldsymbol{D}$ and $\boldsymbol{F}$ ), these structures are relatively free of $A \beta$ deposits. Aq, Aquaduct; $(\mathrm{blm}$, cerebellum; IV, fourth ventricle.

EDTA, 0.86 mm sodium octyl sulfate, $4 \%$ acetonitrile, and $2.5 \%$ tetrahydrofuran, $\mathrm{pH}$ 3. The flow rate was kept at $1.5 \mathrm{ml} / \mathrm{min}$. Biogenic amines and their metabolites were detected by an electrochemical detector (Prostar ECD model 370; Varian).

Open-field task. Open-field paradigm (Crawley, 1999) was used to test novelty-induced exploration and anxiety levels as described previously (Laird et al., 2005; Melnikova et al., 2006). Briefly, the round, white openfield arena had a diameter of $100 \mathrm{~cm}$ and 55-cm-high sidewalls. The illumination consisted of indirect diffuse room light (eight $40 \mathrm{~W}$ bulbs, 12 lux). Each subject was released near the wall and observed for 5 min. Motor activity in the open field was recorded by a computer-based video tracking system (Analysis VP-200; HVS Image). Activity measures included distance traveled (in centimeters), percentage of time spent in active exploration (episodes of movement $\geq 5 \mathrm{~cm} / \mathrm{s}$ ), and speed of movement during active exploration. To analyze anxiety levels, the activity measures were broken down into two zones. Based on our previous studies, a 20 -cm-wide wall zone constituted the most preferred peripheral zone, whereas the rest of the open field was defined as a central zone comprising $\sim 67 \%$ of the arena surface and was most aversive for mice.

Statistical analysis. All statistical analyses were performed using the Prism software (GraphPad). The statistical analysis included the twotailed $t$ test and one- and two-way ANOVA. When $F$ values showed significance at a level of $p<0.05$, the Fisher's post hoc analysis or Newman-Keuls post-test was applied to determine where the differences among groups arose. Data represent mean \pm SEM for each group of animals.

\section{Results}

Progressive loss of MAergic afferents occur after $\mathrm{A} \beta$ deposition in APPswe/PS1 1 E9 mouse

The APPswe/PS1 $\triangle E 9$ mice develop early forebrain $\mathrm{A} \beta$ deposits at $\sim 4$ months of age (Jankowsky et al., 2004). With aging, the A $\beta$ deposition becomes more severe and is associated with astroglial and microglial reactions (Fig. $1 A-C$; supplemental Fig. S1, available at www.jneurosci.org as supplemental material). Although $\mathrm{A} \beta$ deposits were observed in some subcortical regions, ventral midbrain and brainstem regions were generally free of $\mathrm{A} \beta$ deposits (Fig. 1D-F).

To determine whether $A \beta$ pathology is associated with abnormalities in MAergic afferents, sections from brains of $\sim 4-, \sim 12-$, and $\sim 18$-month-old Tg and non-Tg mice were immunostained for 5-HT and TH. Qualitatively, MAergic axons show structural abnormalities that are consistent with axonal dystrophy in the older APPswe/PS1 $\triangle E 9$ mice (Fig. 2A). Furthermore, the density of MAergic axons in the 12- and 18-month-old APPswe/PS1 $1 E 9$ $\mathrm{Tg}$ mice appeared less profuse than in non-Tg mice (Fig. $2 C$ ). To better document the progressive degeneration of the forebrain MAergic axons, we used a stereological approach using the spherical probes (Mouton et al., 2002) to determine the average density of the 5-HT + and $\mathrm{TH}+$ axons in multiple cortical and hippocampal regions. At 4 months of age, when $\mathrm{A} \beta$ deposits are first appearing, the densities of MAergic axons were similar between all genotypes (Figs. $2 B, 3 A, B$ ). However, the losses of MAergic axons from $A P P$ swe/PS1 $\triangle E 9$ mice were clearly apparent at 12 and 18 months of age (Fig. 3). Greater loss of MAergic axons in 18month-old mice demonstrate the progressive nature of axonal degeneration. Furthermore, the loss of $\mathrm{TH}+$ axons was greater than the 5-HT+ axons at both ages. Consistent with the later development of $A \beta$ deposits in amygdala (supplemental Fig. S1, available at www.jneurosci.org as supplemental material), MAergic axons were relatively spared in this region (Fig. 3). The lack of MAergic fiber loss in amygdala, despite the significant $\mathrm{A} \beta$ deposition at 18 months of age, shows that the loss of MAergic axons seen in other brain regions is not attributable to simple space exclusion by the $\mathrm{A} \beta$ deposits. We also confirmed the loss of forebrain MAergic afferents by neurochemical analysis of 5-HT and NA neurotransmitter levels (supplemental Fig. S2, available at www.jneurosci.org as supplemental material). Normal density of MAergic axons in the singly $\mathrm{Tg}(A P P s w e$ or PS1 $\triangle E 9)$ mice (Figs. $2 C, 3 C, D)$ shows that the alterations in MAergic fibers are selectively associated with the development of $A \beta$ deposits.

\section{Neuronal atrophy and overt loss of MAergic neurons in APPswe/PS1 1 E9 mice}

Whereas varying degrees of axonal abnormalities without cell loss are present in other $\mathrm{Tg}$ mouse models of $\mathrm{A} \beta$ deposition (McGowan et al., 2006), the losses of MAergic axons observed here are particularly widespread and severe. Thus, we asked whether death of MAergic neurons accompany the loss of axons 
A

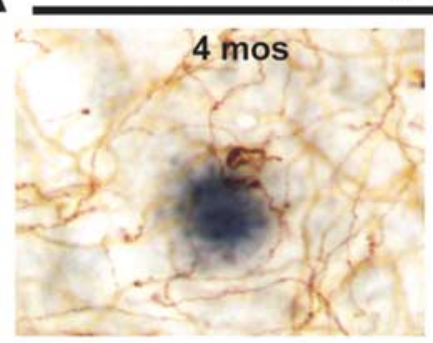

5-HT

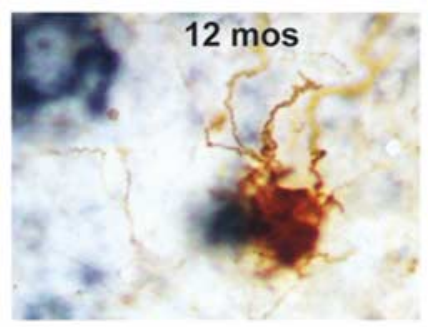

TH

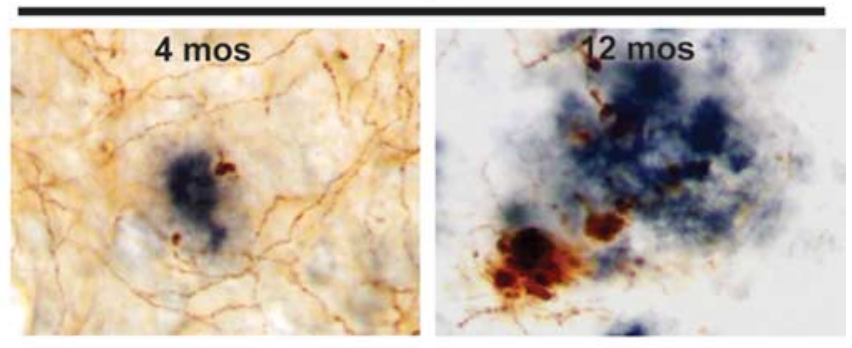

B

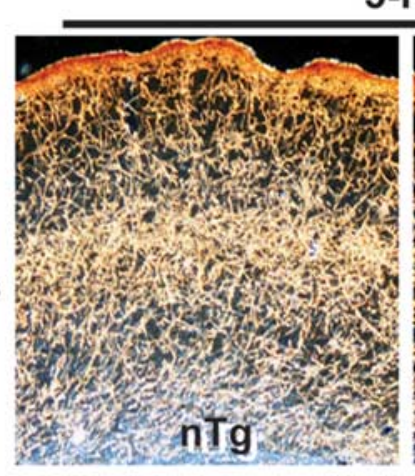

C

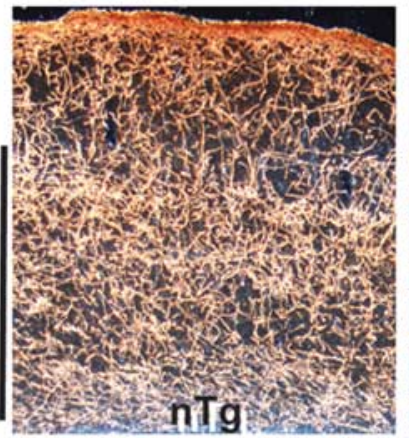

18 mos

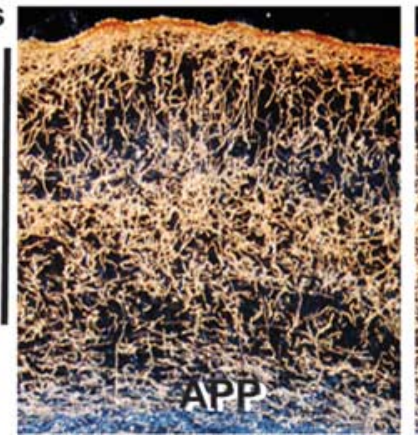

5-HT
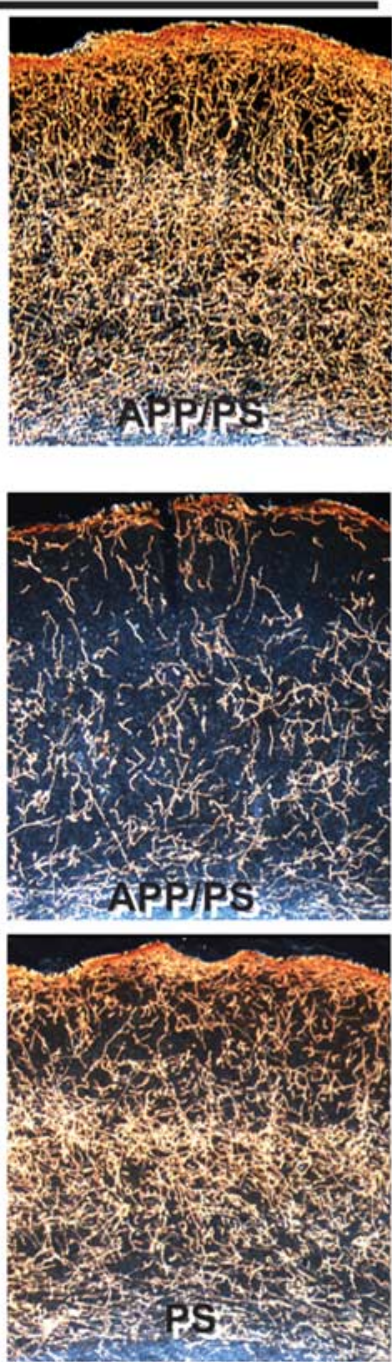

TH
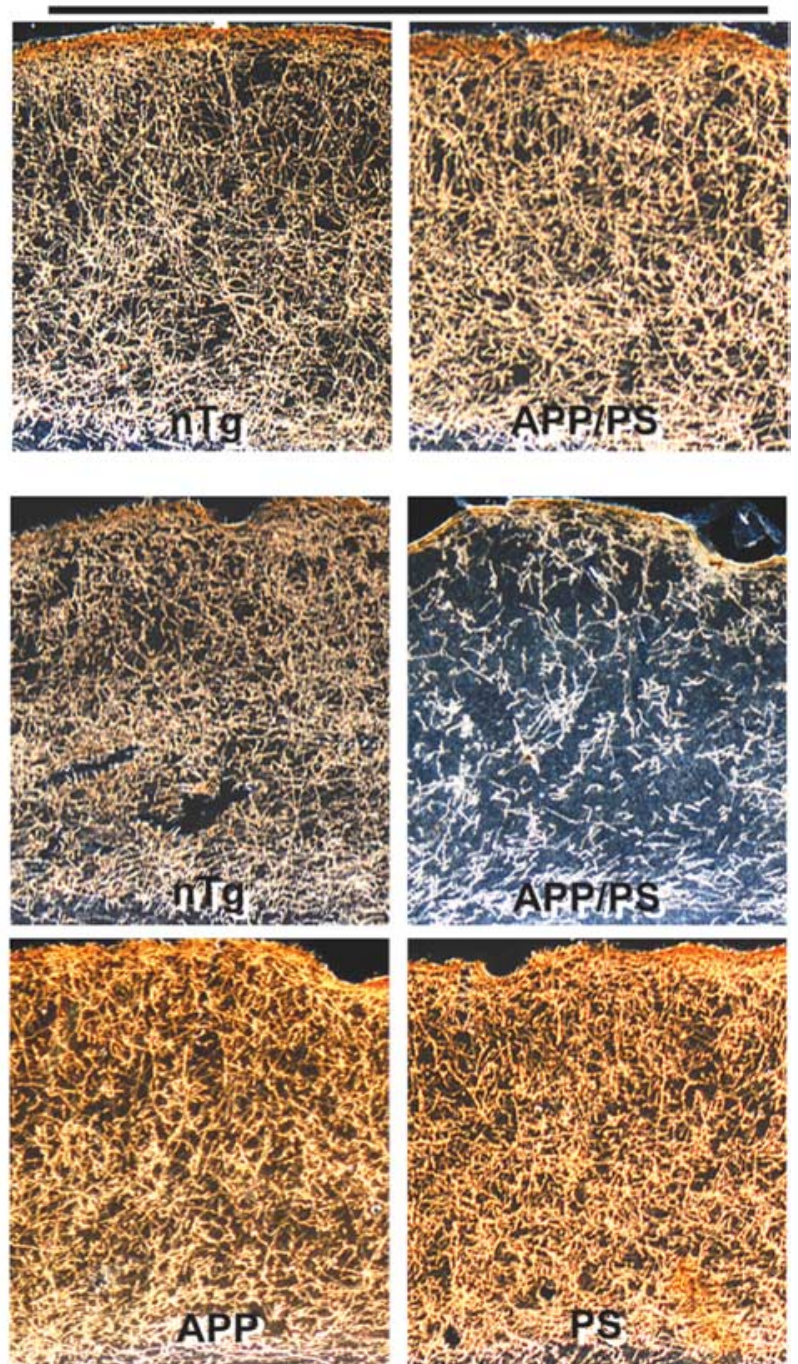

Figure 2. MAergic axonal dystrophy and degeneration in APPswe/PS1 $1 E 9$ mice. $A$, Double labeling of cortex for 5-HT $+/ T H+$ axons (brown) with A $\beta$ deposits (antibody 4G8, blue) in 4- and 12-month-old APPswe/PS1 EE9 mice showing progressive axonal dystrophy with aging. $B, C$, Dark-field images of cortical 5 -HT + and TH + axons at 4 months of age $(\boldsymbol{B})$ and 18 months of age (C). Shown are representative images of non- $\mathrm{Tg}(\mathrm{nTg})$, singly transgenic (APP or PS), and APPSwe/PS1 EE9 (APP/PS) mice. mos, Months.

in the APPswe/PS1 $1 E 9$ mice. We determined the number of MAergic neuronal cell bodies in the APPswe/PS1 $E$ E9 mice by unbiased stereology. Stereological estimation of the number of 5-HT (5-HT+) neurons in the raphe and NA $(\mathrm{TH}+)$ neurons in LC show normal complements of 5-HT and NA neurons in the 12-month-old APPswe/PS1 $\triangle E 9$ mice. However, by 18 months of age, there was $\sim 50 \%$ reduction in MAergic neurons in the $A P P$ swe/PS1 $\triangle E 9$ mice (Fig. 4A-D). To ensure that the loss of MAergic neurons reflects death of these neurons, we also determined the number of non-MAergic neurons in raphe and LC (Fig. 4E). We reasoned that if the loss of MAergic neurons results from the loss of neuronal phenotype rather than cell death, we should see an increase in the number of non-MAergic neurons. Our results show that the numbers of non-MAergic neurons are similar between the non-Tg and the APPswe/PS1 $1 E 9$ mice (Fig. 4E). Because the number of MAergic and non-MAergic neurons are comparable within the region of interest delineated for counting both of these neuronal population, failure to observe changes in the number of non-MAergic neurons is not because of over abundance of non-MAergic neurons. Thus, our results indicate 

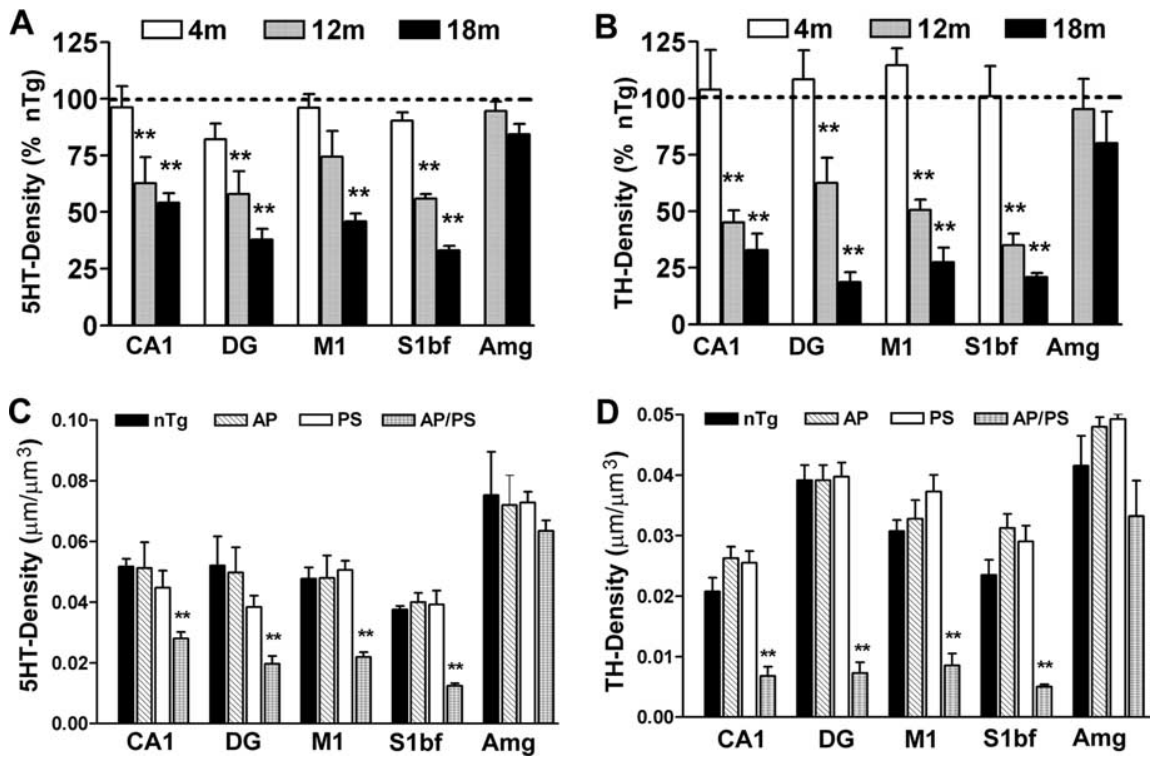

Figure 3. Progressive losses of MAergic axons with aging in the APPswe/PS1 $D E 9$ mice. $\boldsymbol{A}, \boldsymbol{B}$, The densities of 5-HT $+(\boldsymbol{A})$ and $\mathrm{TH}+(\boldsymbol{B})$ axons in hippocampus (CA1 and dentate gyrus), motor cortex (M1), somatosensory cortex-barrel field (S1bf), and amygdala in 4-month-old (4m), 12-month-old (12m), and 18-month-old (18m) APPswe/PS1 $D$ E9 mice. The axon density was normalized to the mean density of age-matched non-Tg mice ( $n=4-8$ mice per group; ${ }^{* *} p<0.01$ vs non-Tg mice). $\boldsymbol{C}, \boldsymbol{D}$, Quantitative analysis of 5-HT $+(\boldsymbol{A})$ and $\mathrm{TH}+(\boldsymbol{B})$ axon densities in hippocampus (CA1, dentate gyrus), motor cortex (M1), barre cortex (S1bf), and amygdala of 18-month-old non-Tg, APPswe-alone (AP), PS1 $D$ E9-alone (PS), and APPswe/PS1 $D$ E9 (AP/PS) mice. Only the AP/PS mice show significantly ( ${ }^{* *} p<0.01 ; n=4-6$ mice per group) lower densities of MAergic axons compared with non-Tg mice. Error bars show SEM. DG, Dentate gyrus; Amg, amygdale; nTg, non-Tg.

to selective loss of MAergic neurons and not mere loss of MAergic phenotype.

To test whether other MAergic neuronal populations degenerate in the APPswe/PS1 $\triangle E 9$ mice, we determined the number of DA neurons in VTA, which innervate the cortex, and the DA neurons in SNpc, which innervate the striatum. Neuronal counts reveal significant loss of DA neurons in VTA, but not in SNpc, of the APPswe/PS1 $\triangle E 9$ mice (Fig. $4 F$ ). The lack of significant neurodegeneration in SNpc is consistent with the previous observation of SNpc in the APPswe/PS1DE9 model (Perez et al., 2005). The selective vulnerability of VTA neurons, compared with SNpc neurons, resembles the situation seen in AD cases (Mann et al., 1987). More important, all of the major MAergic neurons with cortical/hippocampal afferents are vulnerable to progressive neurodegeneration in the APPswe/PS1 $\triangle E 9$ mice.

Because degeneration of MAergic axons precedes loss of MAergic neurons by several months, we hypothesized that the early axonal degeneration may be reflected in the MAergic cell bodies before degeneration as neuronal atrophy. The analyses show that the selective atrophy of vulnerable MAergic neurons in the 12month-old APPswe/PS1 $\triangle E 9$ mice (Fig. 5). Neuronal atrophy is progressive, leading to neuronal loss at 18 months of age. These findings indicate that atrophy of neuronal cell bodies is associated with dying back of MAergic axons, and, only later, is there loss of MAergic neurons.

\section{MAergic neurodegeneration is not associated with accumulations of intracellular $\mathrm{A} \boldsymbol{\beta}$ or abnormally phosphorylated tau in MAergic neurons}

The lack of local $A \beta$ deposits near the MAergic neuronal populations (Fig. $1 D-F$ ) suggest that the progressive MAergic neurodegeneration occurs with exposure of the MAergic axons to distal $\mathrm{A} \beta$ pathology. However, recent studies implicate accumulation of intracellular $A \beta$ as an initiating factor in $\mathrm{AD}$-associated neuronal dysfunction and degeneration (LaFerla et al., 2007). Thus, we examined whether increased accumulation of intracellular $\mathrm{A} \beta$ could explain the progressive degeneration of MAergic neurons. Immunocytochemical analysis using the 4G8 antibody shows increased levels of neuronal 4G8 immunoreactivity in the APPswe and APPswe/PS1 $1 E 9$ mice compared with the non-Tg mice (Fig. 6A). Both $4 \mathrm{G} 8$ and anti-A $\beta 42$ antibodies are very similar in the ability to detect $\mathrm{A} \beta$ deposits (supplemental Fig. S4, available at www.jneurosci.org as supplemental material) In cortical neurons, 4G8 immunostaining revealed punctuate localization similar to abnormal $\mathrm{A} \beta$ localization seen in other mouse models (Oakley et al., 2006; LaFerla et al., 2007) (Fig. 6A; supplemental Fig. S5, available at www. jneurosci.org as supplemental material). However, the anti-A $\beta 42$ antibodies do not convincingly show increased intracellular $\mathrm{A} \beta$ in any neuronal populations (Fig. $6 B$ ). Given the comparable abilities of the antibodies to detect amyloid deposits (supplemental Fig. S4, available at www. jneurosci.org as supplemental material), it is unlikely that the anti-A $\beta 42$ is significantly less sensitive than the $4 \mathrm{G} 8$. Overall, our results indicate that 4G8 staining in Tg mice seen in this study arises from the overexpression of APPswe rather than the accumulation of intracellular $\mathrm{A} \beta$. More important, we do not observe any abnormal pattern of $A \beta$ localization in MAergic neurons or obvious differences in $\mathrm{A} \beta$ localization between APPswe and APPswe/PS1 $\triangle E 9$ mice (Fig. 6; supplemental Fig. S5, available at www.jneurosci.org as supplemental material). Collectively, our results indicate that abnormal accumulation of intracellular $\mathrm{A} \beta$ may not be required for MAergic neurodegeneration in the APPswe/PS1 $1 E 9$ mice.

Because intracellular accumulation of aberrantly phosphorylated tau may mediate neurodegeneration in $\mathrm{AD}$, we examined whether the phosphorylated tau accumulates in MAergic neurons of $A P P s w e / P S 1 \triangle E 9$ mice. Immunocytochemical analysis shows abnormal accumulation of phosphorylated tau in structures around the $\mathrm{A} \beta$ deposits (Fig. $7 A, B$ ). Surprisingly, although these tau-containing elements are believed to be dystrophic axons, they are not coincident with the dystrophic MAergic axons (Fig. 7 A, B). Moreover, immunocytochemical analysis of MAergic cell bodies did not show accumulation of phosphorylated tau within the cell bodies. These results suggest that amyloiddependent neurodegeneration can occur in the absence of obvious tau pathology in degenerating neurons.

MAergic neurodegeneration precedes onset of anxiety-related behaviors in APPswe/PS1DE9 mice

Because MAergic neurons are involved in emotional behaviors (Zweig et al., 1988; Rub et al., 2000; Parvizi et al., 2001; Grudzien et al., 2007), we asked whether MAergic degeneration in APPswe/ $P S 1 \triangle E 9$ mice is associated with any alterations in emotional behaviors. Mice at different ages were monitored for anxietyrelated behavior on an open-field activity test. The decrease in exploration and increase in time spent near the walls of the 
A

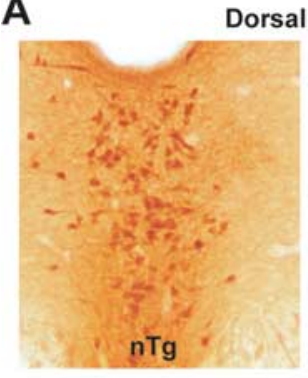

C

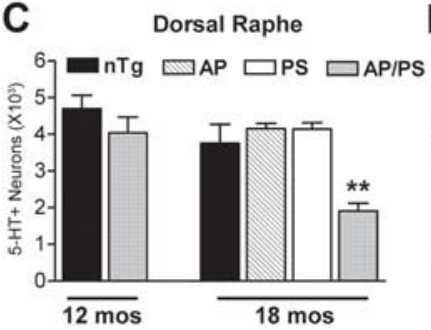

B

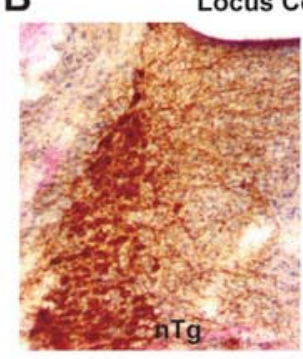

Locus Coeruleus

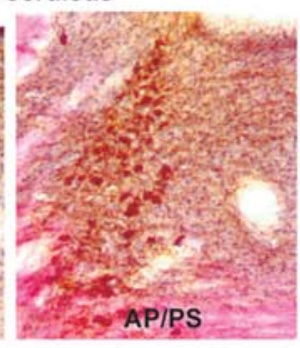

D Locus Coeruleus

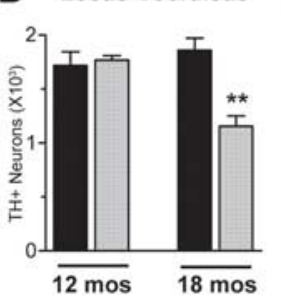

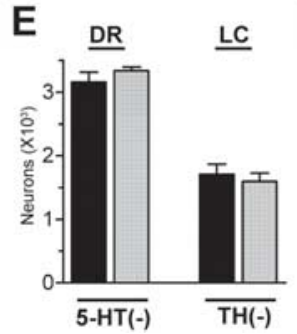

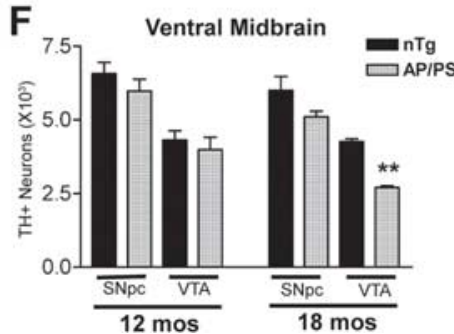

Figure 4. Loss of MAergic neurons in APPswe/PS1 $\triangle E 9$ mice. $\boldsymbol{A}, \boldsymbol{B}$, Representative images of dorsal raphe $(\boldsymbol{A})$, immunostained for 5 -HT + neurons, and $L C(\boldsymbol{B})$, immunostained for TH + neurons, from 18-month-old non-Tg and APPswe/PS1 $\triangle E$ E (AP/PS) mice. C, D, Stereological estimate of 5-HT + neuron number in dorsal raphe (C) and TH + neuron number in LC (D) of 12-and 18-month-old non-Tg and Tg mice. Only the 18-month-old AP/PS mice show significant loss of MAergic neurons ( $n=4-8$ per group; ${ }^{* *} p<0.01$ vs non-Tg mice). Analysis of median raphe also showed similar loss of neurons (data not shown). E, Stereological estimates of the number of Nissl-stained 5-HT(-) and TH(-) neurons in dorsal raphe (DR) and LC, respectively, of 18-month-old non-Tg and AP/PS mice. Loss of neuronal phenotype without cell loss would lead to increased number of $5-\mathrm{HT}(-)$ and TH( - ) neurons. $\boldsymbol{F}$, The numbers of TH + dopaminergic neurons in SNpc and VTA in 12 - and 18-month-old non-Tg and AP/PS mice. There is a significant loss of TH + dopaminergic neurons in VTA of 18 -month-old AP/PS mice ( $n=4-8$ per group; ** $p<0.01)$. Symbol designations are as shown in C. Error bars show SEM. non-Tg, Non-Tg.

activity box (thigmotaxis) are indicators of increased anxiety-related behaviors. Our analysis shows that the APPswel PS1 $\triangle E 9$ mice exhibit decreased noveltyinduced exploration at 24 months of age (Fig. 8A) and increased thigmotaxis at 18 and 24 months of age (Fig. 8 B). These results indicate that the APPswe/PS1 $\triangle E 9$ mice develop anxiety-related behaviors at 18 and 24 months of age. Thus, MAergic neurodegeneration, occurring before 12 months of age, precedes the onset of abnormal emotional behaviors in APPswe/PS1 1 E9 mice.

\section{Discussion}

The results of the present study demonstrate that the APPswe/PS1 1 E9 mouse model of $\mathrm{AD}$ recapitulates the progressive degeneration of MAergic neurons occurring in $\mathrm{AD}$. Our results extend the previous studies showing the late-onset loss of 5-HT/NA neurotransmitter levels (Szapacs et al., 2004) and the loss of LC neurons (O'Neil et al., 2007) in the aged APPswe/PS1 $1 E 9$ mouse model by providing a comprehensive structural, spatial, and temporal analysis. Our results have significant implications. First, the results establish that robust neurodegeneration can occur in a mouse model of cerebral $\mathrm{A} \beta$ pathology in the absence of neurofibrillary pathology. Second, MAergic neurodegeneration starts at axon terminals and progresses to cell bodies, similar to the progression of MAergic neurodegeneration proposed for $\mathrm{AD}$ cases (Marcyniuk et al., 1986; German et al., 1992; Parvizi et al., 2001). Significantly, we could not document an obvious increase in accumulation of intracellular $A \beta$ as a function of neurodegeneration. We note that the term " $\mathrm{A} \beta$ pathology"
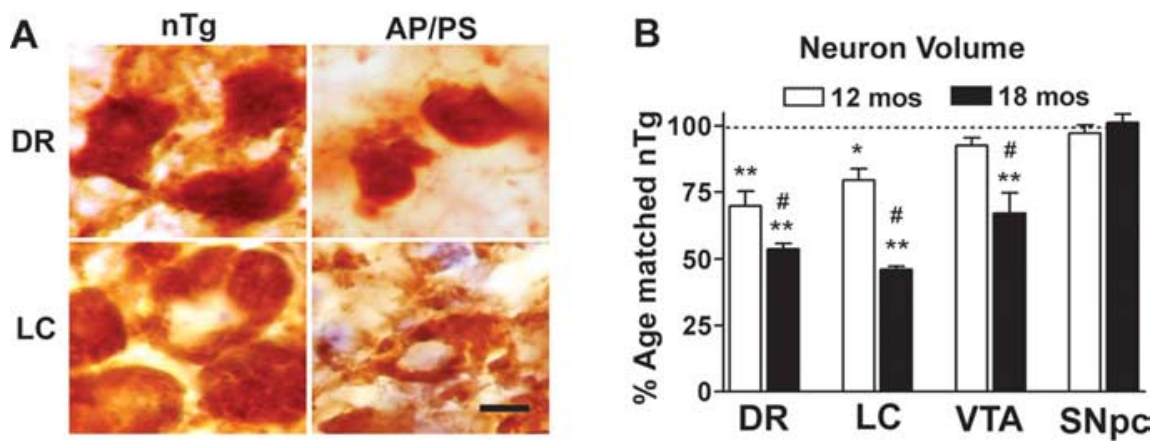

Figure 5. Atrophy of MA neurons precedes cell loss in APPSwe/PS1 E9 mice. A, High-magnification images of 5-HT + neurons in dorsal raphe and TH + neurons in LC from 18-month-old non-Tg and APPswe/PS1 $\triangle E 9$ (AP/PS) mice. Scale bar, $20 \mu \mathrm{m}$. $\boldsymbol{B}$ 列 subjects. Shown are percentages of neuronal volumes of age-matched non-Tg mice $\left(n=4-6\right.$ mice per group; ${ }^{* *} p<0.01$ or ${ }^{*} p<0.05$ vs non-Tg mice; ${ }^{*} p<0.05$ vs 12 -month-old AP/PS mice). Error bars show SEM. Actual neuronal volumes are shown in supplemental table S1. DR, dorsal raphe; $\mathrm{nTg}$, non-Tg; mos, months.

refers to a collection of events that include $\mathrm{A} \beta$ deposition and local glial responses

It has long been proposed that a significant portion of neurodegeneration in $\mathrm{AD}$ is initiated at the axon terminals (Marcyniuk et al., 1986; German et al., 1992; Coleman and Yao, 2003), and we provide in vivo evidence for the temporal and spatial relationship between $\mathrm{A} \beta$ pathology, axonal degeneration, and death of neurons. Specifically, the onset and progression of forebrain $A \beta$ pathology precedes progressively severe loss of cortical MAergic axons and subsequent loss of MAergic neurons. Neuron loss in the APPswe/PS1 $\triangle E 9$ mice occurs without significant local amyloid deposition near the degenerating cell bodies, indicating that exposure of the MAergic afferents to cortical/hippocampal $\mathrm{A} \beta$ pathology ( $\mathrm{A} \beta$ deposits and/or $\mathrm{A} \beta$-dependent abnormalities) leads to axonal degeneration, followed by the loss of MAergic neurons. This overall pattern of neurodegeneration is consistent 


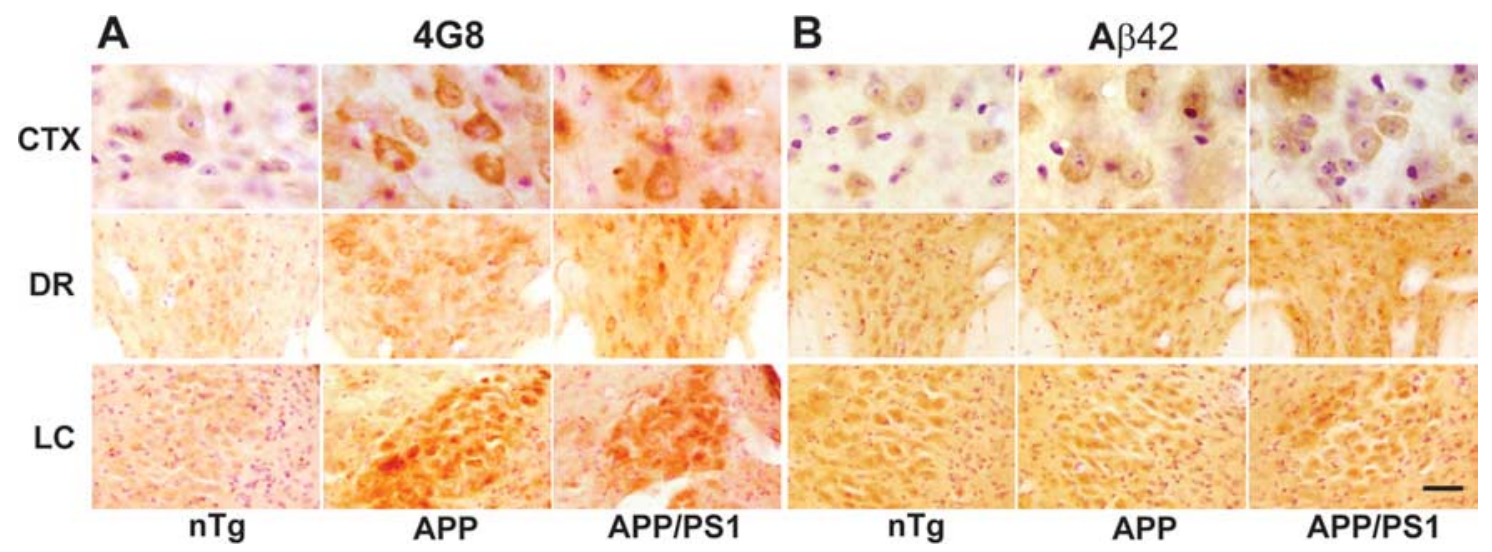

Figure 6. MAergic neurodegeneration occurs without accumulation of intracellular A $\beta$ in MAergic neurons. Brain sections from 8-month-old non-Tg (nTg), APPswe (APP), and APPswe/PS1 $\triangle E 9$ (APP/PS1) mice, containing cortex (CTX; scale bar, $50 \mu \mathrm{m})$, dorsal raphe (DR; scale bar, $100 \mu \mathrm{m})$, and LC (scale bar, $100 \mu \mathrm{m})$, were immunostained using the $4 \mathrm{G} 8$ antibody ( $A$ ) or an anti-A $\beta 42$ antibody $(\boldsymbol{B})$. Note the increased $4 \mathrm{G} 8$ staining in the Tg mice. In contrast, anti-A $\beta 42$ immunoreactivity in $\mathrm{Tg}$ mice is not notably different from nTg mice. The $4 \mathrm{G} 8 \mathrm{immunoreactivity} \mathrm{is} \mathrm{very} \mathrm{similar}$ between APP and APP/PS1 mice.

with findings in $\mathrm{AD}$ in which the MAergic neurodegeneration occurs without local A $\beta$ pathology (Marcyniuk et al., 1986; German et al., 1992; Parvizi et al., 2001). Rather, MAergic neurodegeneration in $\mathrm{AD}$ is selective for neurons that project to cortical regions (Marcyniuk et al., 1986; German et al., 1992; Parvizi et al., 2001). This distal axonopathy provides an explanation of why the correlation between the extent of local $\mathrm{A} \beta$ deposition and neurodegeneration is poor in $\mathrm{AD}$. In addition to the lack of extracellular $\mathrm{A} \beta$ deposits near the cell bodies, the MAergic neurons do not show obvious increases in the intracellular $A \beta$. Although we cannot exclude possible involvement of intracellular $\mathrm{A} \beta$ production by the MAergic neurons, our studies could not document an obvious increase in the accumulation of intracellular $A \beta$ as a function of neurodegeneration.

Distal axonopathy is not a unique feature of neurodegeneration in $\mathrm{AD}$ or in the APPswe/PS1 $\triangle E 9$ model because many neurodegenerative diseases and models of diseases have features indicating the presence of distal axonopathy. Furthermore, although we believe extracellular $\mathrm{A} \beta$ species are responsible for neurodegeneration of MAergic neurons, cell-autonomous or cell-intrinsic pathogenic factors can also cause a distal axonopathy type of neurodegeneration. For example, distal axonopathy is clearly a neurodegenerative feature in human amyotrophic lateral sclerosis (ALS) and in a mutant SOD1 Tg mouse model of ALS (Fischer et al., 2004). What distinguishes neurodegeneration in the $\mathrm{AD}$ cases and APPswe/PS1 $E 9$ model from other neurodegenerative diseases/models is that the vulnerability of neurons is somehow linked to exposure of axon terminals to $\mathrm{A} \beta$ pathology. For example, whereas LC neurons degenerate in both AD and Parkinson's disease (PD), the pattern of degeneration is disease specific (German et al., 1992). Although only the LC neurons with cortical projections degenerate in $\mathrm{AD}, \mathrm{LC}$ neurons in $\mathrm{PD}$ cases show a more uniform pattern of degeneration. This study concluded that LC neurons degenerate in PD because of the pathological process affecting all LC neurons whereas LC neurons in $\mathrm{AD}$ degenerate as a secondary response to cortical amyloid pathology. Similarly, although DA neurons degenerate in both the APPswe/PS1 $\triangle E 9$ model (this study) and in the mutant SOD1 Tg model of ALS (Kostic et al., 1997), the vulnerable populations are very different. Consistent with general vulnerability of SNpc DA neurons to intrinsic and extrinsic toxic insults, the SNpc neurons show greater vulnerability in the mutant SOD1 models (Kostic et al., 1997). However, selective degeneration of
VTA DA neurons in the APPswe/PS1 $\triangle E 9$ model suggests that cortical projections of VTA neurons contribute to degeneration of these neurons. Early intrinsic factors causing distal axonopathy, possibly by axonal transport defects, could be involved in AD pathogenesis (Terry, 1996; Coleman and Yao, 2003). If such is the case, our studies and studies of human AD cases (Marcyniuk et al., 1986; German et al., 1992; Parvizi et al., 2001) add support for the possibility that such intrinsic defects are caused by cortical amyloid pathology.

Our ongoing studies also support the view that $A \beta$ accumulations have a direct impact on MAergic neurodegeneration. Specifically, $\mathrm{A} \beta$ immunization leads to significant attenuation of MAergic neurodegeneration in the APPswe/PS1 $E 9$ mouse model (Y. Liu, M. K. Lee, J. Troncoso, and E. Oh, unpublished observations). Although we believe that MAergic neurodegeneration is $\mathrm{A} \beta$ dependent, it is possible that the insoluble $\mathrm{A} \beta$ deposits are not the toxic agents. For example, it is possible that smaller oligomeric species of A $\beta$ (Kayed et al., 2003; Lesne et al., 2006) could be responsible for MAergic neurodegeneration. Alternatively, neuroinflammation caused by $\mathrm{A} \beta$ deposits could be important for neurodegeneration (McGeer et al., 2005). Regardless, our observation now allows for future evaluation of these and other processes in $\mathrm{AD}$-associated neurodegeneration.

The APPswe/PS1 $\triangle E 9$ mouse model exhibits a particularly aggressive $\mathrm{A} \beta$ pathology. Thus, the lack of convincing subcortical neurodegeneration in other Tg mouse models may be related to less aggressive $\mathrm{A} \beta$ pathology in these models. This view is supported by our finding in the $t$ TA/APP mouse model (Jankowsky et al., 2005), in which aggressive forebrain-specific $A \beta$ accumulation leads to progressive MAergic neurodegeneration (Y. Liu and M. K. Lee, unpublished observation). However, even in the $\mathrm{Tg}$ lines with less aggressive $\mathrm{A} \beta$ pathology, aberrant expression of cell-cycle-related proteins occur in the 5-HT and NA neurons but not in the cholinergic neurons (Yang et al., 2006), suggesting that MAergic neurons are particularly vulnerable to increased levels of $\mathrm{A} \beta$. Consistent with this view, a recent report shows that despite axonal abnormalities, Ach neurons do not show degenerative changes in the aged APPswe/PS1 $1 E 9$ mouse model (Perez et al., 2007). Although a complete analysis of the Ach system is in progress, our initial analyses of Ach afferents also indicate that Ach fibers are more preserved than the MAergic afferents and (supplemental Fig. S3, available at www.jneurosci.org as supplemental material). The lack of Ach neuron loss in Tg mice may 
A

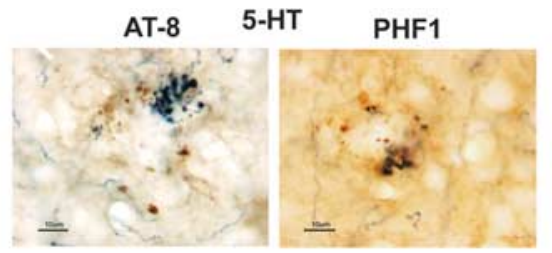

B

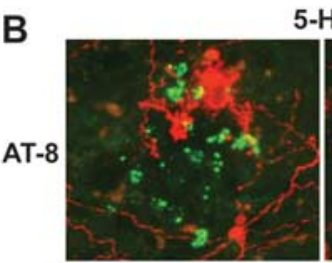

5-HT

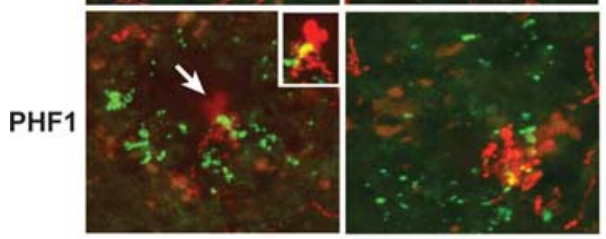

C
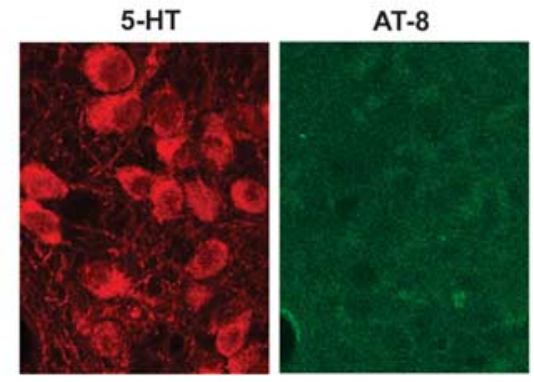

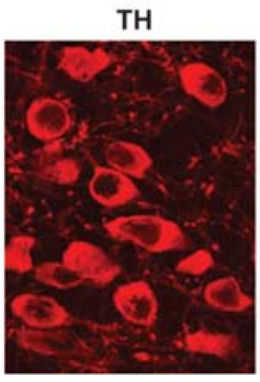

TH

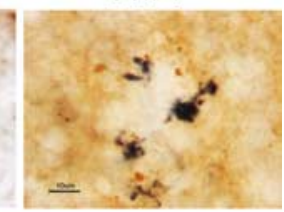

$\mathrm{TH}$
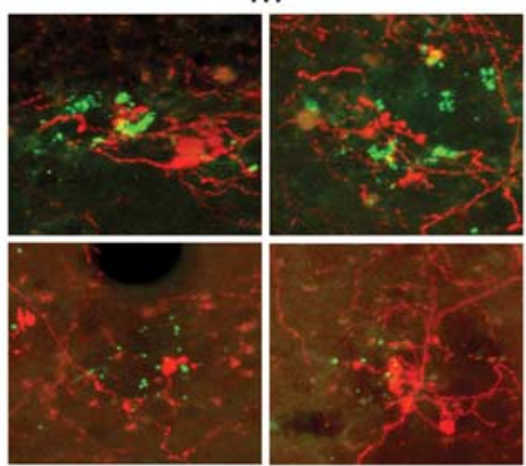

AT-8

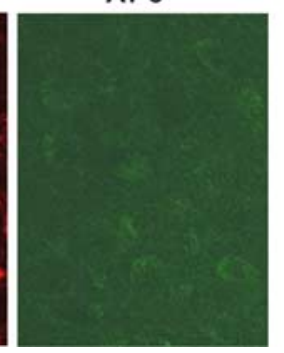

Figure 7. MAergic neurodegeneration is not associated with accumulation of phosphorylated tau in MAergic neurites or neurons. A, Brain sections double immunostained for phosphorylated tau (AT-8 or PHF1; brown) and MAergic axons (5-HT or TH; blue). Both phosphorylated tau and dystrophic MAergic axons localize around the amyloid deposits. $B$, Confocal immunofluorescence analysis of sections from APPSwe/PS1 1 E9 mice (12 months old) reacted for phosphorylated tau (AT-8 or PHF1; green) and MAergic axons (5-HT or TH; red). Stacked images reconstructed from $10-16$ optical sections are shown. The images show that very little, if any, overlap of phosphorylated tau with the dystrophic MAergic axons. The inset shows $180^{\circ}$ rotation of the area indicated by the arrow. The areas of overlap (yellow) result as artifacts of "transparency" settings for reconstruction and do not represent coincidence within the same optical section(s). C, Although we are able to clearly document phosphorylated tau associated with amyloid deposits $(\boldsymbol{A}, \boldsymbol{B})$, we could not document neuronal staining. Double-immunofluorescence labeling of phosho-tau (AT8; green) with 5-HT (red) or TH (red) shows lack of significant AT-8 immunoreactivity in MAergic neurons.

A

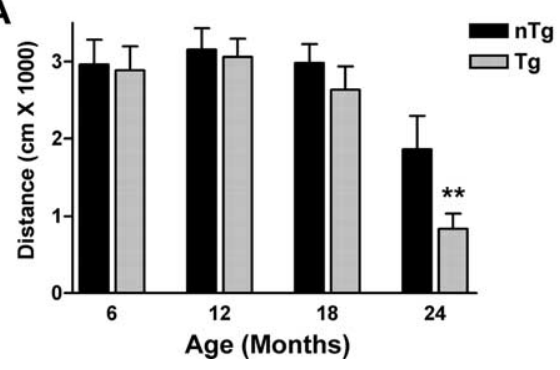

B

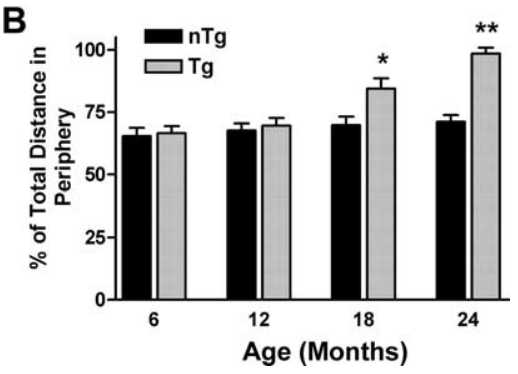

Figure 8. Increased anxiety-related behaviors in aged APPSwe/PS1 $E 9$ mice. $\boldsymbol{A}$, Reduced novelty-induced exploration in APPSwe/PS1 1 E9 mice. The motor activity in the open-field test (total distance traveled in centimeters \pm SEM) is lower in 24-month-old Tg mice. $B$, Increased thigmotaxis in APPswe/PS1 $\triangle E 9$ mice. The values are percentages ( \pm SEM) of total distance traveled $(\boldsymbol{A})$ within the periphery of the activity box. All values are mean $\pm \operatorname{SEM}\left({ }^{*} p<0.05 ;{ }^{* *} p<0.01 ; n=8-12\right.$ mice per group). $\mathrm{nTg}$, Non-Tg.

reflect species difference in cellular vulnerability. Alternatively, longer cortical afferents of MAergic neurons, compared with the Ach neurons, may increase vulnerability of MAergic neurons to defects in retrograde support. Because human neurons would have afferents of substantial length, even between cortical regions, differences in vulnerabilities may not be as apparent. One could also propose that MAergic neurons are generally more vulnerable to the neurotoxic insults. However, this simple view does not explain the sparing of $\mathrm{SNpc}$ neurons in our model (Fig. 4F). Thus, although intrinsic vulnerability of MAergic neurons could be a factor, it is clear that additional factors that are specific for the APPswe/PS1 $1 E 9$ mouse model determine the pattern of MAergic neurodegeneration. Again, this view is consistent with the observed pattern of MAergic neurodegeneration in $\mathrm{AD}$ cases (Marcyniuk et al., 1986; Mann et al., 1987; German et al., 1992; Parvizi et al., 2001; Lyness et al., 2003).

Whereas tau pathology is proposed as a necessary mediator of $A \beta$-dependent neurodegeneration, our studies indicate that tau pathology is not required for neurodegeneration in the APPswe/PS1 $E$ E9 mice. However, significant a body of evidence indicates that tau abnormalities are likely contributing factors in neurodegeneration occurring in human $\mathrm{AD}$ cases (McGowan et al., 2006). Thus, the presence of tau pathology may exacerbate $A \beta$-associated neurodegeneration in mice. Given that tau levels modulate the $\mathrm{A} \beta$-dependent cognitive defect in the $h A P P$ mice (Roberson et al., 2007), it will be of significant interest to determine whether tau is required for the neurodegeneration in the APPswe/PS1 $\triangle E 9$ mice. However, it appears that reductions in endogenous tau does not affect amyloid-associated neuropathology in the hAPP mice (Roberson et al., 2007), and the lack of abnormal tau in dystrophic MAergic axons seen here suggests that tau pathology may not be required for $\mathrm{A} \beta$ associated neurodegeneration in vivo.

Another important implication of our results is that degeneration of the MAergic neurons may promote $\mathrm{AD}$-related behavioral abnormalities and pathology in $\mathrm{Tg}$ mouse models. In addition to the temporal relationship between MAergic degeneration and the onset of anxiety-related behaviors, progression of MAergic neurodegeneration coincides with the onset and the progression of cognitive abnormalities in the APPswe/PS1 $1 \triangle 9$ mice (supplemental Fig. S6, available at www.jneurosci.org as supplemental material). This association is consistent with the fact that although defective 5-HT or NA neurotransmission does not affect cognitive function, the combined antagonism of both systems or the addition of anticholinergic compounds can induce cognitive defects (Kenton et al., 2007). Significantly, toxin-induced degeneration of NA neurons in APP 
(amyloid precursor protein) Tg mice exacerbates amyloid pathology and cognitive dysfunction (Heneka et al., 2006; Kalinin et al., 2007), and chronic administration of 5-HT reuptake inhibitor attenuates pathology and behavioral abnormalities in the 3XTgAD mice (Nelson et al., 2007). Thus, severe degeneration of MAergic neurons may have significant impact on the onset and progression of both the behavioral and the pathological abnormalities in the APPswe/PS1 $1 E 9$ mice and in AD.

In summary, the APPswe/PS1 $\triangle E 9$ mouse model of $A \beta$ deposition recapitulates the progressive MAergic neurodegeneration observed in $\mathrm{AD}$ without additional toxic genes. Furthermore, MAergic neurodegeneration in the APPswe/PS1DE9 mouse model initially targets synaptic terminals/distal axons, resembling the MAergic degeneration in AD cases. Collectively, our results indicate that the APPswe/PS1 $\triangle E 9$ mouse model provides a robust platform to define in vivo mechanisms of amyloiddependent neurodegeneration and to test neuroprotective strategies for $\mathrm{AD}$.

\section{References}

Boncristiano S, Calhoun ME, Kelly PH, Pfeifer M, Bondolfi L, Stalder M, Phinney AL, Abramowski D, Sturchler-Pierrat C, Enz A, Sommer B, Staufenbiel M, Jucker M (2002) Cholinergic changes in the APP23 transgenic mouse model of cerebral amyloidosis. J Neurosci 22:3234-3243.

Calhoun ME, Wiederhold KH, Abramowski D, Phinney AL, Probst A, Sturchler-Pierrat C, Staufenbiel M, Sommer B, Jucker M (1998) Neuron loss in APP transgenic mice. Nature 395:755-756.

Coleman PD, Yao PJ (2003) Synaptic slaughter in Alzheimer's disease. Neurobiol Aging 24:1023-1027.

Crawley JN (1999) Behavioral phenotyping of transgenic and knockout mice: experimental design and evaluation of general health, sensory functions, motor abilities, and specific behavioral tests. Brain Res 835:18-26.

Fischer LR, Culver DG, Tennant P, Davis AA, Wang MS, Castellano-Sanchez A, Khan J, Polak MA, Glass JD (2004) Amyotrophic lateral sclerosis is a distal axonopathy: evidence in mice and man. Exp Neurol 185:232-240.

German DC, Manaye KF, White CL III, Woodward DJ, McIntire DD, Smith WK, Kalaria RN, Mann DMA (1992) Disease-specific patterns of locus coeruleus cell loss. Ann Neurol 32:667-676.

Grudzien A, Shaw P, Weintraub S, Bigio E, Mash DC, Mesulam MM (2007) Locus coeruleus neurofibrillary degeneration in aging, mild cognitive impairment and early Alzheimer's disease. Neurobiol Aging 28:327-335.

Gundersen HJG, Bendtsen TF, Korbo L, Marcussen N, Moller A, Nielsen K, Nyengaard JR, Pakkenberg B, Sorensen FB, Vesterby A, West MJ (1988a) Some new, simple and efficient stereological methods and their use in pathological research and diagnosis. APMIS 96:379-394.

Gundersen HJG, Bagger P, Bendtsen TF, Evans SM, Korbo L, Marcussen N, Moller A, Nielsen K, Nyengaard JR, Pakkenberg B, Sorensen FB, Vesterby A, West MJ (1988b) The new stereological tools: disector, fractionator, nucleator and point sampled intercepts and their use in pathological research and diagnosis. APMIS 96:857-881.

Heneka MT, Ramanathan M, Jacobs AH, Dumitrescu-Ozimek L, BilkeiGorzo A, Debeir T, Sastre M, Galldiks N, Zimmer A, Hoehn M, Heiss WD, Klockgether T, Staufenbiel M (2006) Locus ceruleus degeneration promotes Alzheimer pathogenesis in amyloid precursor protein 23 transgenic mice. J Neurosci 26:1343-1354.

Irizarry MC, McNamara M, Fedorchak K, Hsiao K, Hyman BT (1997a) $\mathrm{App}_{\mathrm{Sw}}$ transgenic mice develop age-related $\mathrm{A} \beta$ deposits and neuropil abnormalities, but no neuronal loss in CA1. J Neuropathol Exp Neurol 56:965-973.

Irizarry MC, Soriano F, McNamara M, Page KJ, Schenk D, Games D, Hyman BT (1997b) A $\beta$ deposition is associated with neuropil changes, but not with overt neuronal loss in the human amyloid precursor protein V717F (PDAPP) transgenic mouse. J Neurosci 17:7053-7059.

Jankowsky JL, Fadale DJ, Anderson J, Xu GM, Gonzales V, Jenkins NA, Copeland NG, Lee MK, Younkin LH, Wagner SL, Younkin SG, Borchelt DR (2004) Mutant presenilins specifically elevate the levels of the 42 residue \{beta\}-amyloid peptide in vivo: evidence for augmentation of a 42 specific \{gamma\} secretase. Hum Mol Genet 13:159-170.

Jankowsky JL, Slunt HH, Gonzales V, Savonenko AV, Wen JC, Jenkins NA,
Copeland NG, Younkin LH, Lester HA, Younkin SG, Borchelt DR (2005) Persistent amyloidosis following suppression of Abeta production in a transgenic model of Alzheimer disease. PLoS Med 2:e355.

Kalinin S, Gavrilyuk V, Polak PE, Vasser R, Zhao J, Heneka MT, Feinstein DL (2007) Noradrenaline deficiency in brain increases beta-amyloid plaque burden in an animal model of Alzheimer's disease. Neurobiol Aging 28:1206-1214.

Kayed R, Head E, Thompson JL, McIntire TM, Milton SC, Cotman CW, Glabe CG (2003) Common structure of soluble amyloid oligomers implies common mechanism of pathogenesis. Science 300:486-489.

Kenton L, Boon F, Cain DP (2007) Combined but not individual administration of beta-adrenergic and serotonergic antagonists impairs water maze acquisition in the rat. Neuropsychopharmacology 33:1298-1311.

Kostic V, Gurney ME, Deng H-X, Siddique T, Epstein CJ, Przedborski S (1997) Midbrain dopaminergic neuronal degeneration in a transgenic mouse model of familial amyotrophic lateral sclerosis. Ann Neurol 41:497-504.

LaFerla FM, Green KN, Oddo S (2007) Intracellular amyloid-beta in Alzheimer's disease. Nat Rev Neurosci 8:499-509.

Laird FM, Cai HSAV, Farah MH, He K, Melnikova TWH, Chiang H-C, Xu G, Koliatsos VE, Borchelt DR, Price DL, Lee HK, Wong PC (2005) BACE1, a major determinant of selective vulnerability of the brain to $A \beta$ amyloidogenesis is essential for cognitive, emotional and synaptic functions. J Neurosci 25:11693-11709.

Lesne S, Koh MT, Kotilinek L, Kayed R, Glabe CG, Yang A, Gallagher M, Ashe $\mathrm{KH}$ (2006) A specific amyloid-[beta] protein assembly in the brain impairs memory. Nature 440:352-357.

Lyness SA, Zarow C, Chui HC (2003) Neuron loss in key cholinergic and aminergic nuclei in Alzheimer disease: a meta-analysis. Neurobiol Aging 24:1-23.

Mamounas LA, Altar CA, Blue ME, Kaplan DR, Tessarollo L, Lyons WE (2000) BDNF promotes the regenerative sprouting, but not survival, of injured serotonergic axons in the adult rat brain. J Neurosci 20:771-782.

Mann DMA, Yates PO, Marcyniuk B (1987) Dopaminergic neurotransmitter systems in Alzheimer's disease and in Down's syndrome at middle age. J Neurol Neurosurg Psychiatry 50:341-344.

Marcyniuk B, Mann DMA, Yates PO (1986) The topography of cell loss from locus caeruleus in Alzheimer's disease. J Neurol Sci 76:335-345.

Mattson MP (1995) Free radicals and disruption of neuronal ion homeostasis in AD: a role for amyloid $\beta$-peptide? Neurobiol Aging 16:679-682.

Mayhew TM (1992) A review of recent advances in stereology for quantifying neural structure. J Neurocytol 21:313-328.

McGeer EG, Klegeris A, McGeer PL (2005) Inflammation, the complement system and the diseases of aging. Neurobiol Aging 26 [Suppl 1]:94-97.

McGowan E, Eriksen J, Hutton M (2006) A decade of modeling Alzheimer's disease in transgenic mice. Trends Genet 22:281-289.

Melnikova T, Savonenko A, Wang Q, Liang X, Hand T, Wu L, Kaufmann WE, Vehmas A, Andreasson KI (2006) Cycloxygenase-2 activity promotes cognitive deficits but not increased amyloid burden in a model of Alzheimer's disease in a sex-dimorphic pattern. Neuroscience 141:1149-1162.

Mouton PR, Gokhale AM, Ward NL, West MJ (2002) Stereological length estimation using spherical probes. J Microsc 206:54-64.

Nelson RL, Guo Z, Halagappa VM, Pearson M, Gray AJ, Matsuoka Y, Brown M, Martin B, Iyun T, Maudsley S, Clark RF, Mattson MP (2007) Prophylactic treatment with paroxetine ameliorates behavioral deficits and retards the development of amyloid and tau pathologies in 3xTgAD mice. Exp Neurol 205:166-176.

Oakley H, Cole SL, Logan S, Maus E, Shao P, Craft J, Guillozet-Bongaarts A, Ohno M, Disterhoft J, Van Eldik L, Berry R, Vassar R (2006) Intraneuronal beta-amyloid aggregates, neurodegeneration, and neuron loss in transgenic mice with five familial Alzheimer's disease mutations: potential factors in amyloid plaque formation. J Neurosci 26:10129-10140.

O'Neil JN, Mouton PR, Tizabi Y, Ottinger MA, Lei DL, Ingram DK, Manaye KF (2007) Catecholaminergic neuronal loss in locus coeruleus of aged female dtg APP/PS1 mice. J Chem Neuroanat 34:102-107.

Parvizi J, Van Hoesen GW, Damasio A (2001) The selective vulnerability of brainstem nuclei to Alzheimer's disease. Ann Neurol 49:53-66.

Paxinos G, Franklin KBJ (2001) The mouse brain in sterotaxic coordinates, Ed 2. San Diego: Academic.

Perez SE, Lazarov O, Koprich JB, Chen EY, Rodriguez-Menendez V, Lipton JW, Sisodia SS, Mufson EJ (2005) Nigrostriatal dysfunction in familial 
Alzheimer's disease-linked APPswe/PS1DeltaE9 transgenic mice. J Neurosci 25:10220-10229.

Perez SE, Dar S, Ikonomovic MD, DeKosky ST, Mufson EJ (2007) Cholinergic forebrain degeneration in the APPswe/PS1DeltaE9 transgenic mouse. Neurobiol Dis 28:3-15.

Roberson ED, Scearce-Levie K, Palop JJ, Yan F, Cheng IH, Wu T, Gerstein H, Yu GQ, Mucke L (2007) Reducing endogenous tau ameliorates amyloid beta-induced deficits in an Alzheimer's disease mouse model. Science 316:750-754.

Rub U, Del Tredici K, Schultz C, Thal DR, Braak E, Braak H (2000) The evolution of Alzheimer's disease-related cytoskeletal pathology in the human raphe nuclei. Neuropathol Appl Neurobiol 26:553-567.

Savonenko A, Xu GM, Melnikova T, Morton JL, Gonzales V, Wong MP, Price DL, Tang F, Markowska AL, Borchelt DR (2005) Episodic-like memory deficits in the APPswe/PS1dE9 mouse model of Alzheimer's disease: relationships to $\beta$-amyloid deposition and neurotransmitter abnormalities. Neurobiol Dis 18:602-617.

Schmitz C, Rutten BP, Pielen A, Schafer S, Wirths O, Tremp G, Czech C, Blanchard V, Multhaup G, Rezaie P, Korr H, Steinbusch HW, Pradier L, Bayer TA (2004) Hippocampal neuron loss exceeds amyloid plaque load in a transgenic mouse model of Alzheimer's disease. Am J Pathol 164:1495-1502.

Sisodia SS, George-Hyslop PH (2002) gamma-Secretase, Notch, Abeta and Alzheimer's disease: where do the presenilins fit in? Nat Rev Neurosci 3:281-290.
Szapacs ME, Numis AL, Andrews AM (2004) Late onset loss of hippocampal 5-HT and NE is accompanied by increases in BDNF protein expression in mice co-expressing mutant APP and PS1. Neurobiol Dis 16:572-580.

Terry RD (1996) The pathogenesis of Alzheimer disease: an alternative to the amyloid hypothesis. J Neuropathol Exp Neurol 55:1023-1025.

Thomas B, von Coelln R, Mandir AS, Trinkaus DB, Farah MH, Leong LK, Calingasan NY, Flint BM, Dawson VL, Dawson TM (2007) MPTP and DSP-4 susceptibility of substantia nigra and locus coeruleus catecholaminergic neurons in mice is independent of parkin activity. Neurobiol Dis 26:312-322.

Wong TP, Debeir T, Duff K, Cuello C (1999) Reorganization of cholinergic terminals in the cerebral cortex and hippocampus in transgenic mice carrying mutated presenilin-1 and amyloid precursor protein transgenes. J Neurosci 19:2706-2716.

Yang Y, Varvel NH, Lamb BT, Herrup K (2006) Ectopic cell cycle events link human Alzheimer's disease and amyloid precursor protein transgenic mouse models. J Neurosci 26:775-784.

Yankner BA (1996) Mechanisms of neuronal degeneration in Alzheimer's disease. Neuron 16:921-932.

Zweig RM, Ross CA, Hedreen JC, Steele C, Cardillo JE, Whitehouse PJ, Folstein MF, Price DL (1988) The neuropathology of aminergic nuclei in Alzheimer's disease. Ann Neurol 24:233-242. 